\title{
Fatigue Failure of Notched Specimen-A Strain-Life Approach
}

\author{
Bikash Joadder, Jagabandhu Shit, Sanjib Acharyya*, Sankar Dhar
}

Department of Mechanical Engineering, Jadavpur University, Kolkata, India.

E-mail: "skacharyya@mech.jdvu.ac

Received July $22^{\text {nd }}, 2011$; revised September $9^{\text {th }}, 2011$; accepted November $15^{\text {th }}, 2011$.

\begin{abstract}
Failure cycles of notched round specimens under strain controlled cyclic loading are predicted using strain-life relations obtained from experiment for plain fatigue round specimens. For notched specimens, maximum strain occurs at notch root and is different from applied controlled strain. The maximum strain is computed by appropriate Finite element analysis using the FE software ABAQUS. FE model and material parameters are validated by comparing the FE results and experimental results of $L C F$ tests of round specimens. This value of maximum strain is used for prediction of failure cycles. Prediction is compared with the experimental results. The results show good matching.
\end{abstract}

Keywords: Strain-Life Equation, Failure Cycle, Notched Specimen, LCF, Cyclic Plasticity

\section{Introduction}

Fatigue has become progressively more relevant for technological development in automobiles, aircraft, compressors, pumps, turbines, etc., subject to repeated loading and vibration. Today it is often stated that fatigue accounts for at least 90 percent of all service failures due to mechanical causes [1]. A fatigue failure is particularly insidious because it occurs without any obvious warning. Therefore methodology for fatigue failure prediction is of immense importance in industry and practice. One of the popular age old stress based method for predicting fatigue failure is based on S-N curve which was later on modified to consider the effect of mean stress, effect of low amplitude spikes in load spectra and statistical nature of fatigue. Using Miner's rule [2] the method can be applied for cumulative load cycles to assess the cumulative damage. But all these application is valid for High cycle fatigue where the stress and strain do not exceed the elastic limit.

For low-cycle fatigue conditions where the stress is high enough to create plastic deformation, fatigue failure results from cyclic strain rather than from cyclic stress.

Low-cycle fatigue is usually characterised by the Coffin-Manson relation [3-6], best described by the material relation between plastic strain amplitude and life which is known as strain life curve. An important use of the strain-life curve is to predict the life for crack initiation at notches in machine parts where the nominal stresses are elastic but the local stresses and strains at the root of a notch are inelastic. Neuber [7] proposed a simple function of nominal stress remotely measured from the notch, which can be used to predict failure at the notch. Basquin $[8,9]$ observed that Stress-Life data could be modeled using a power relationship, which results in a straight line on a log-log plot. This observation corresponds to elastic material behavior in the strain-life approach. Later the aproaches suggested by Basquin and Coffin-Manson are combined together to develop the strain life curve applicable over the whole regim (HCF and LCF).

A. H. Noroozi, G. Glinka, S. Lambert [10] developed unified two-parameter fatigue crack growth driving force model to account for the residual stress and subsequently the stress ratio effect on fatigue crack growth. Ostash, Panasyuk and Kostyk [11] modelled fatigue fracture of materials as a process of initiation of a macrocrack of a particular length (material constant), which is successsively repeated (step-by-step) during its growth and the 'local stress range vs. macrocrack initiation period relationship for notched specimens, might be applied to the determination of the "macrocrack growth rate, da/dN, vs. effective stress intensity factor range relationship.

A fatigue crack growth model under constant amplitude loading has been developed by Pandey and Chand [12] considering energy balance during crack growth. Plastic energy dissipated during growth of a crack within 
a small area, known as process zone at the tip of the crack and the area below cyclic stress-strain curve was used in the energy balance.

S. K. Visvanatha, P. V. Straznicky, R. L. Hewitt, 2000 [13] studied the influence of strain estimating techniques on life predictions using the local strain approach. Knop, Jones, Molent and Wang (2000) [14] focus on the development of a simple method that combines modern constitutive theory with either Neuber's, or Glinka's approach to calculate the localised notch strains to study the effects of cyclic loading, mean stress relaxation and its effect of fatigue damage. Jae-Yong Lim, Seong-Gu Hong, Soon-Bok Lee, (2005) [15] proposed a methodology of life prediction of fatigue crack initiation for the cyclically non-stabilized and non-Masing steel. Modeling of fatigue crack growth from a notch was attempted by Ding, Feng and Jiang (2006) [16] to describe the crack growth at notches quantitatively with a detailed consideration of the cyclic plasticity of the material. Round compact specimens made of 1070 steel were subjected to Mode I cyclic loading with different R-ratios at room temperature. The approach developed was able to quantitatively capture the crack growth behavior near the notch. An implicit gradient application to fatigue of sharp notches and weldments has been investigated by R. Tovo, P. Livieri (2006) [17]. This paper addresses the problem of stress singularities at the tip of sharp V-notches by means of a non-local implicit gradient approach. Ku- jawski and Stoychev (2006) [18] investigated the effects of the internal stresses on crack initiation at notches. Fatigue strength assessment of welded joints from the integration of Paris' law to a synthesis based on the notch stress intensity factors to the uncracked geometries has been studied by B. Atzori, P. Lazzarin, G. Meneghett (2007) [19]. The effect of notch plasticity on the behaviour of fatigue cracks emanating from edge notches in highstrength $\beta$-titanium alloys has been studied by $\mathrm{M}$. Benedetti, V. Fontanari, G. Lu tjering, J. Albrecht (2007) [20]. Prediction of fatigue initiation lives in notched Ti 6246 specimens based on numerical models for predicting LCF initiation is studied by M. T. Whittaker, S. J. Williams and W. J. Evans, 2008, [21]. W. J. Evans, R. Lancaster, A. Steele , M. Whittaker, N. Jones , 2009 [22] explored the low cycle fatigue (LCF) characteristics of three alloy variants and the assessment of methods for predicting the observed lives. Fatigue life prediction of notched components based on a new nonlinear Continuum Damage Mechanics model has been studied by $\mathrm{S}$. Giancane, R. Nobile, F. W. Panella, V. Dattoma, 2010 [23]. A CDM (continuum damage mechanics) model for damage evaluation is here considered and applied to the study of two different typologies of notched and cylindrical specimens. Prediction of fatigue lifetime under multiaxial cyclic loading using finite element analysis studied by Guo-Qin Sun, De-Guang Shang, 2010 [24]. Here, Life prediction for GH4169 super-alloy thin tubular and notched specimens were investigated under proportional and non-proportional loading with elastic-plastic finite element analysis (FEA). Fatigue life prediction of small notched Ti-6Al-4V specimens using critical distance is studied by Yoichi Yamashita, Yusuke Ueda, Hiroshi Kuroki , Masaharu Shinozaki, 2010 [25]. Daniel Leidermark, Johan Moverareab, Kjell Simonssona, Sören Sjöström, Sten Johansson, 2010 [26] investigated the fatigue crack initiation in notched single-crystal test specimens of material MD2. A critical plane approach is adopted, in which the total strain ranges on the discrete slip planes are evaluated. Furthermore, a Coffin-Manson type of expression is used to describe the number of cycles to fatigue crack initiation. An investigation of fatigue of a notched member, studied by Zengliang Gao, Baoxiang Qiu, Xiaogui Wang, Y. Jiang 2010 [27] based on the tension-compression, torsion, and axial-torsion fatigue experiments conducted on notched shaft specimens made of $16 \mathrm{MnR}$ steel, local stress fatigue life prediction approaches were evaluated.

The objective of this work is to predict the failure cycle of notched round specimen of material SS316 under strain controlled cyclic loading using combined form of Coffin-Mansion relation and Basin's equation. Strainlife equation is derived from experimental results of plain fatigue round specimen under strain controlled cyclic loading. In case of plain fatigue round specimen the strain remains uniform through out the cross section and hence the maximum strain is easily known from the applied strain amplitude. But in the case of notched specimen maximum strain occurs at notch root and failure of the specimen is governed by the value of this maximum strain. Therefore computation of maximum strain in notched specimen is highly important and the accuracy of prediction mainly related to the accuracy in evaluation of maximum strain. Finite element analysis with suitable material model with the implementation of Armstrong and Frederick's (1966) kinematic hardening rule clubbed with cyclic hardening is used to compute the maximum strain in the notched specimen. Initially FE model together with material model are validated by comparing the FE simulated results and experimental results of LCF tests at different strain amplitudes. Then FE results for notched specimen are generated using the same material model. The maximum strain is evaluated from FE results and is used to predict the failure cycle for notched specimen from strain life relation already generated from plain fatigue test data. Prediction is compared with the experimental results. 


\section{Material}

316 Stainless steel (SS316) is selected as material for the investigation. The chemical compositions of SS316 are shown in Table 1. Grade 316 is the standard molybdenum-bearing grade, second in importance to 304 amongst the austenitic stainless steels. Grade $316 \mathrm{~L}$, the low carbon version of 316 is immune from sensitisation (grain boundary carbide precipitation). Thus it is extensively used in heavy gauge welded components (over about 6 $\mathrm{mm})$.

In the current investigation, cylindrical specimens (notched specimens or specimens without notch) made from the hot-rolled round bar are used to study the notch effect on fatigue life of the material. Before machining, the material was heat-treated (solution annealing, section) at $1120^{\circ} \mathrm{C}$ for 1 hour followed by water-cooling. After machining, grinding is also done for better surface finish. Three different types of specimens of different configurations (plain tensile specimen, plain fatigue specimen, notched fatigue specimens etc.) were made. Different notches were made varying notch angle and notch depth.

\section{Experiments}

In this investigation all the experiments are performed with an Instron-8801 load frame with 8800 electronics and computer controller. An Extensometer of $12.5 \mathrm{~mm}$ gauge length was used for the strain measurement. The specimen matrix as shown in Table 2 is used to obtain experimental data.

The type of test and material data obtained from these tests are listed as

1) Tensile test with standard round specimens.

2) Low cycle fatigue test of round (without notch) specimens are performed and failure cycles for different strain amplitudes are determined. From the saturated loop data, the coefficients of non-linear kinematic hardening and of cyclic hardening parameters are obtained. Coefficients for plastic strain-life equation and elastic strain-life equation are evaluated from failure cycle data.

3) Low cycle fatigue test for failure cycles of various notched specimens $\left(30^{\circ}, 45^{\circ}, 60^{\circ}\right)$ for different strain amplitudes.

\subsection{Tensile Test}

Tensile tests are done in Instron- 8800 machine at a fixed displacement rate of $1 \mathrm{~mm} / \mathrm{min}$ using Blue Hill software. The Strain measurement was done by an extensometer. The experiment was repeated with five specimens and the values for yield stress, young's modulus and stressstrain data upto failure were obtained as statistical average. Output data of plain tensile test is shown in Table 3. These data are required as input for FE simulation.

Table 1. Chemical composition of SS316.

\begin{tabular}{|c|c|c|c|c|c|c|c|c|}
\hline $\mathrm{Fe}(\%)$ & $\mathrm{C}(\%)$ & $\mathrm{Cr}(\%)$ & $\mathrm{Ni}(\%)$ & Mo (\%) & Mn (\%) & $\mathrm{Si}(\%)$ & $\mathrm{P}(\%)$ & S (\%) \\
\hline - & $<0.03$ & $16-18.5$ & $10-14$ & $2-3$ & $<2$ & $<1$ & $<0.045$ & $<0.03$ \\
\hline
\end{tabular}

Table 2. Specimen matrix.

\begin{tabular}{|c|c|c|c|c|c|c|c|c|c|}
\hline \multirow{2}{*}{$\begin{array}{l}\text { Name of } \\
\text { the Specimen }\end{array}$} & \multirow{2}{*}{ Quantity } & \multirow{2}{*}{$\begin{array}{l}\text { Gauge Length } \\
(\mathrm{mm})(\mathrm{GL})\end{array}$} & \multirow{2}{*}{$\begin{array}{l}\text { Gauge Diameter } \\
\quad(\mathrm{mm})(\mathrm{GD})\end{array}$} & \multicolumn{3}{|c|}{ Notch Angle } & \multirow{2}{*}{$\begin{array}{l}\text { Notch Diameter } \\
(\mathrm{mm})\end{array}$} & \multirow{2}{*}{$\begin{array}{l}\text { Notch Depth } \\
\quad(\mathrm{mm})\end{array}$} & \multirow{2}{*}{$\begin{array}{l}\text { Grip Diameter } \\
(\mathrm{mm})\end{array}$} \\
\hline & & & & 300 & 450 & 600 & & & \\
\hline Notch Fatigue & 11 & 15 & 10 & 3 & 4 & 4 & 6 & 2 & 11.5 \\
\hline Plain Fatigue & 6 & 15 & 7.5 & $\mathrm{X}$ & $\mathrm{X}$ & $\mathrm{X}$ & $\mathrm{X}$ & $\mathrm{X}$ & 10 \\
\hline Plain Tensile & 5 & 30 & 6.5 & $X$ & $\mathrm{X}$ & $\mathrm{X}$ & $\mathrm{X}$ & $\mathrm{X}$ & 10 \\
\hline
\end{tabular}

Table 3. Table for out put data of plain tensile test.

\begin{tabular}{|c|c|c|c|c|}
\hline $\begin{array}{l}\text { Yield stress } \\
\quad(\mathrm{MPa})\end{array}$ & $\begin{array}{l}\text { Ultimate Stress } \\
\quad(\mathrm{MPa})\end{array}$ & $\begin{array}{c}\text { Tensile strain at Break } \\
\text { (\%) }\end{array}$ & $\begin{array}{c}\text { Tensile strain at maximum Load } \\
\text { (\%) }\end{array}$ & $\begin{array}{l}\text { Modulus (E-Modulus) } \\
\text { (Gpa) }\end{array}$ \\
\hline 267.27 & 700.78 & 82.03 & 78.86 & 165.68 \\
\hline
\end{tabular}




\subsection{Low Cycle Fatigue Test of Round Specimens}

Strain controlled Low Cycle fatigue tests for plain round specimens were done upto failure for six different strain amplitudes $(0.3 \%, 0.5 \%, 0.6 \%, 0.75 \%, 1.0 \%$ and $1.2 \%)$ using SAX software as shown in Table 4. The stressstrain data and the failure cycles were obtained for each strain amplitude. The stress-strain curve for saturated loop is shown in Figure 1 for strain amplitude of $0.5 \%$. All the tests are performed with the uniform strain rate of $10^{-2} / \mathrm{s}$. The failure cycles were obtained from experiments for each strain amplitude.

\subsubsection{Extraction of Material Hardening Parameters from Low Cycle Fatigue Test}

Kinematic and Isotropic hardening parameters required to model the stress-strain loop data for low cycle fatigue loading were evaluated from the experimental loop stressstrain data at saturated level. The values obtained are tuned to match the loop stress-strain curve of different strain amplitudes. The values were used to simulate load vs. strain and stress vs. strain curve under cyclic loading for plain fatigue specimens for different strain amplitudes. The simulated and experimental results corresponding to $0.5 \%$ strain amplitude have been shown in Figures 2 and 3 respectively.

Coefficients of combined form of Coffin-Mansion relation and Basin's equation for Strain-life relation were extracted from the failure cycles at different strain amplitudes.

FE Model of Low Cycle Fatigue Test:

Low cycle fatigue test for plain round and notched specimens were simulated using the FE software ABAQUS. Inputs for geometry, loading, material parameters and boundary conditions were properly fed with combined hardening material model. Then Load vs strain and stress vs strain curves were generated from FE results. Peak stresses were also evaluated at different cycles for each strain amplitude.

Nonlinear Kinematic Hardening Model:

In FE simulation of LCF, Armstrong, Frederick (1966) kinematic hardening model has been used. They introduced a kinematic hardening rule containing a "recall" term, which incorporates the fading memory effect of the strain path and essentially makes the rule nonlinear in nature. This kinematic hardening rule is given below:

Table 4. Failure cycles from low cycle plain fatigue test for different strain amplitudes.

\begin{tabular}{lcccccc}
\hline Specimen No. & PF1 & PF2 & PF3 & PF4 & PF5 & PF6 \\
\hline True strain (\%) & 0.3 & 0.5 & 0.6 & 0.75 & 1.0 & 1.2 \\
Failure cycles & 18837 & 1602 & 1224 & 562 & 247 & 210 \\
\hline
\end{tabular}

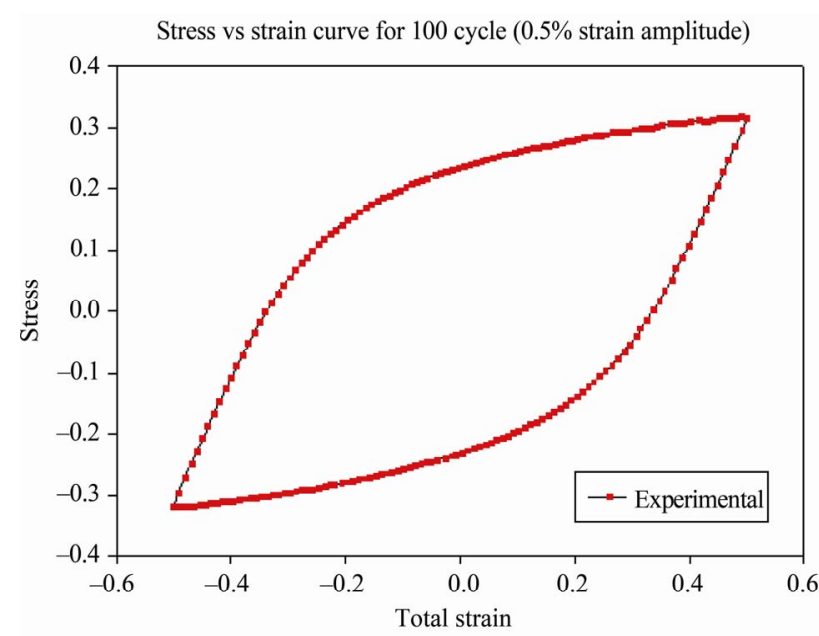

Figure 1. Stress vs strain curve of $5 \%$ strain amplitude.

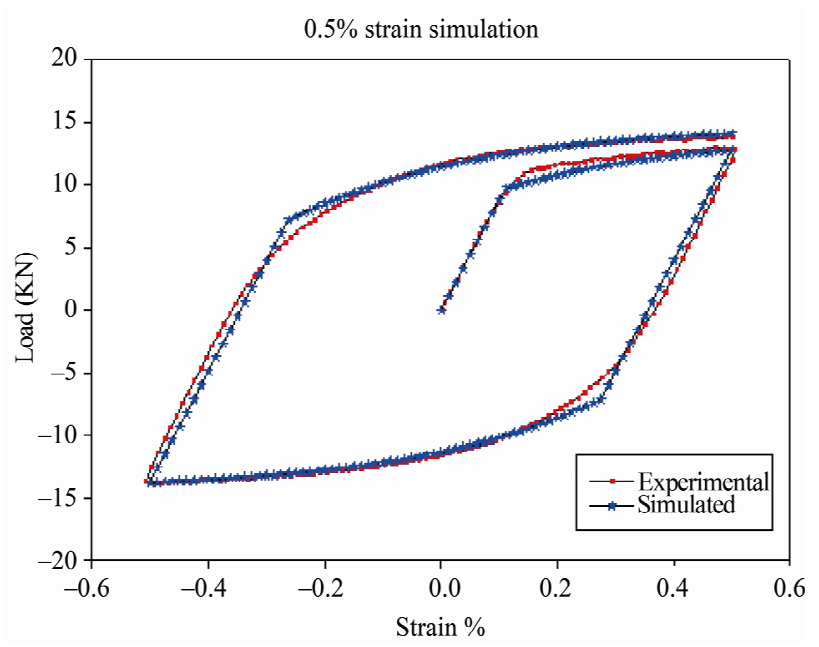

Figure 2. Load vs strain curve for the $1^{\text {st }}$ cycle $(0.5 \%$ strain amplitude).

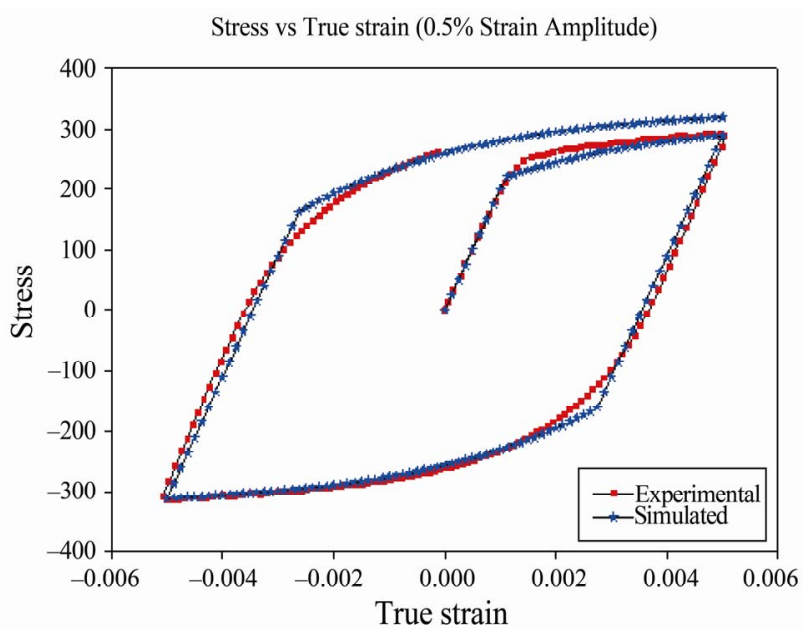

Figure 3. Stress vs strain curve for the $1^{\text {st }}$ cycle $(0.5 \%$ strain amplitude). 


$$
\mathrm{d} \bar{X}=C \mathrm{~d} \overline{\varepsilon^{p}}-\gamma \bar{X} \mathrm{~d} p
$$

when

$$
\mathrm{d} p=\left|\mathrm{d} \varepsilon^{p}\right|=\sqrt{\mathrm{d} \varepsilon^{p} \cdot \mathrm{d} \varepsilon^{p}}
$$

here $\mathrm{C}$ and $\gamma$ are material constants.

Increase in the value of $\mathrm{C}$ would improve the simulation during the initial nonlinear part, but the simulation for the rest of the curve would suffer. Another limitation of this model is its inability to produce constant plastic modulus exhibited by experiments for a high strain range, for which model always stabilizes to zero plastic modulus.

The isotropic hardening behavior of the model defines the evolution of the size of the yield surface, $\sigma^{0}$, as a function of the equivalent plastic strain, $\varepsilon_{e q}^{p}$. This evolution can be introduced by specifying $\sigma^{0}$ directly as a function of $\varepsilon_{e q}^{p}$. The simple exponential law is

$$
\sigma^{0}=\left.\sigma\right|_{0}+Q_{\alpha}\left(1-e^{-B \varepsilon_{e q}^{p}}\right)
$$

Initially all these material parameters $\left(\mathrm{C}, \gamma, Q_{\dot{\alpha}}, \mathrm{B}, \sigma^{0}\right)$ required to simulate cyclic loading were computed from experimental results of LCF test of plain round specimens at $0.5 \%$ strain amplitude and then, finally, tuned to give optimum matching between experimental and FE simulated results at various strain amplitudes. While finding the optimum values of hardening parameters two features have been considered. First, the predictability of load vs strain curve for the first cycle and the second one is the peak stresses at different cycles and both the features at different strain amplitudes.

The FE results based on this optimum values of material parameters are shown in Figures 2-7 and compared with that of experimental results at different strain amplitudes and found to be satisfactory. From the results

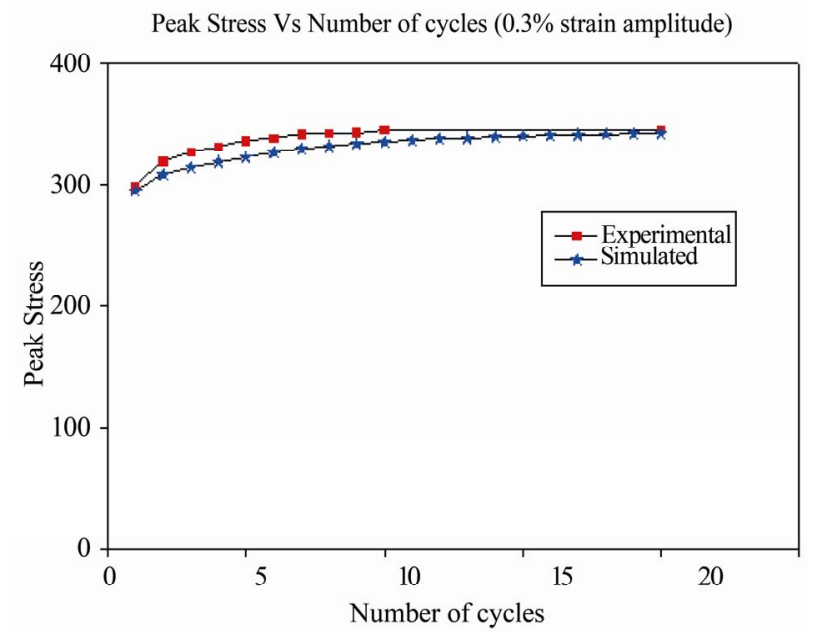

Figure 4. Peak stress vs number of cycles $(0.3 \%$ strain amplitude).

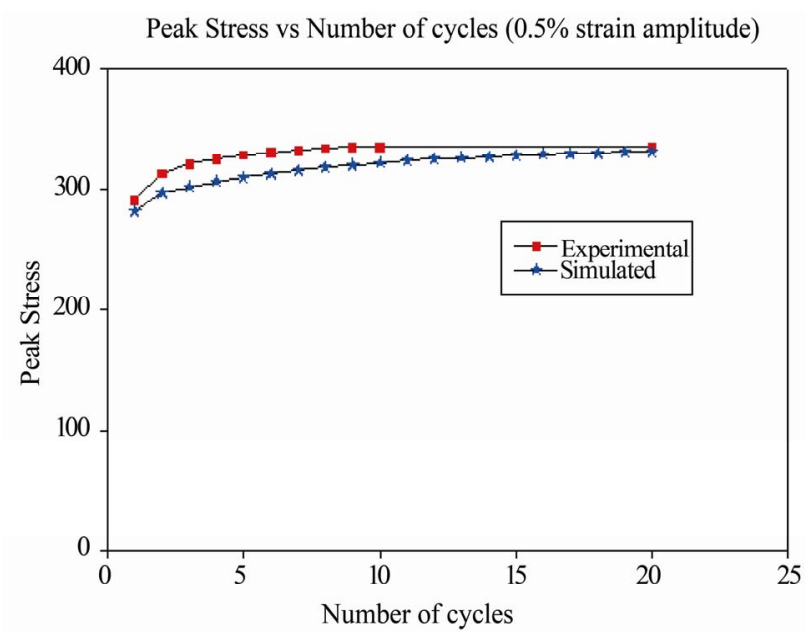

Figure 5. Peak Stress vs number of cycles (0.5\% strain amplitude).

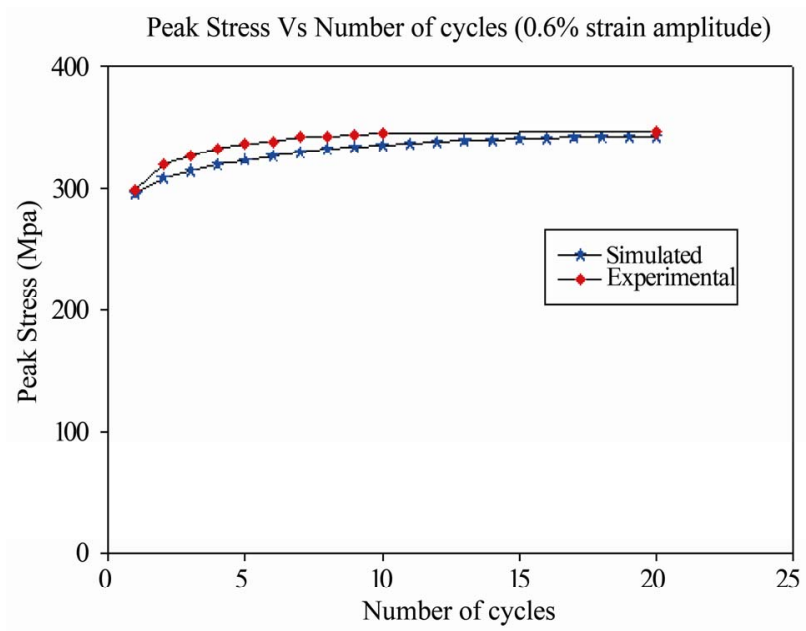

Figure 6. Peak Stress vs number of cycles $(0.6 \%$ strain amplitude).

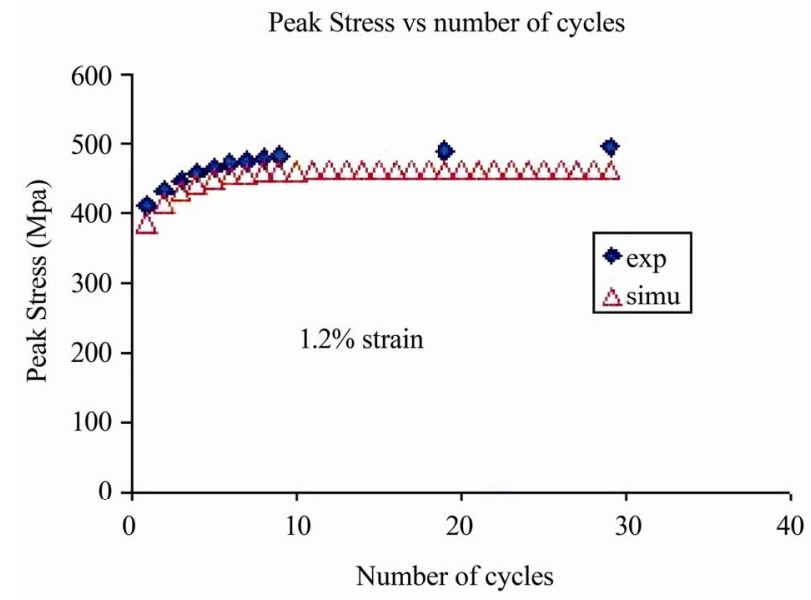

Figure 7. Peak Stress vs number of cycles (1.2\% strain amplitude). 
it is accepted that this hardening parameters obtained can be used to simulate the stress - strain behaveiour of notched fatigue specimens under cyclic loading. The final material parameters extracted from experimental fatigue test are given in Table 5.

\subsubsection{Extraction of Strain-Life Equation from LCF Test of Plain Round Specimens}

Strain Life Curve: The plastic strain life curve is plotted from LCF test of plain round specimens test data using Coffin-Manson relation, which is best described by

$$
\frac{\Delta \varepsilon_{p}}{2}=\varepsilon_{f}^{\prime}(2 N)^{c}
$$

where, $\mathrm{N}=$ No. of Failure cycles, $\varepsilon_{f}^{\prime}=$ Fatigue ductility coefficient, $\mathrm{c}=$ Fatigue ductility exponent.

The values of $\varepsilon_{f}^{\prime}$ and $\mathrm{c}$ are evaluated from the linear fitting of $\log \left(\frac{\Delta \varepsilon_{p}}{2}\right)$ vs $\log (2 \mathrm{~N})$ that is shown in Figure 8.

$$
\text { Hence } \mathrm{c}=-0.4503 \quad \varepsilon_{f}^{\prime}=\operatorname{antilog}(0.8674)=0.1357
$$

\section{Elastic Strain Fatigue Life Curve:}

The relation between elastic strain and fatigue life in the high cycle fatigue can be described by the Basquin's reformulated equation. Basquin's reformulated equation is best described by

$$
\sigma_{a}=\frac{\Delta \varepsilon_{e}}{2} E=\sigma_{f}^{\prime}(2 N)^{b}
$$

where, $\sigma_{f}^{\prime}=$ fatigue strength coefficient and $b=$ Fatigue strength exponent.
The values of $\sigma_{f}^{\prime}$ and $\mathrm{b}$ are evaluated from the linear fitting of $\log \left(\frac{\Delta \varepsilon_{e}}{2}\right)$ vs $\log (2 N)$ that is shown in Figure 9.

$$
b=-0.2092 \text { and } \frac{\sigma_{f}^{\prime}}{E}=\operatorname{antilog}(-2.0761)=0.00856
$$

An equation valid for the entire range of fatigue can be obtained by superposition of Equations (4) and (5) and given as

$$
\frac{\Delta \varepsilon_{t}}{2}=\frac{\Delta \varepsilon_{e}}{2}+\frac{\Delta \varepsilon_{p}}{2}=\frac{\sigma_{f}^{\prime}(2 N)^{b}}{E}+\varepsilon_{f}^{\prime}(2 N)^{c}
$$

The values of the coefficients $\sigma_{f}^{\prime}, b, \varepsilon_{f}^{\prime}, c$ obtained from LCF test data of plain round specimens with different strain amplitudes are put in the Equation (6) and the material strain-life curve for the entire range (LCF and HCF) based on this equation is shown in Figure 10.

\section{FE Simulation of Notched Specimen}

Notched fatigue specimens with different notch angles and depths of notch are modeled and FE simulated results are generated for fatigue loading at different strain amplitudes in ABAQUS. The material constants for modeling kinematic hardening and cyclic hardening are obtained from LCF test of plain round specimens. The value of maximum plastic strain, elastic strain and total strain at saturated loop are obtained as FE outputs. The average strain at the notch tip element is also computed. The contour plot for FE results for one specimen is shown in Figure 11.

Table 5. Material parameters from experimental cyclic stress strain results.

\begin{tabular}{ccccccc}
\hline Young Modulus & Poisson's Ratio & $\left(\sigma_{0}\right)$ & \multicolumn{2}{c}{ Knematic Hardening Parameter } & \multicolumn{2}{c}{ Cyclic Hardening Parameter } \\
\hline$(\mathrm{E})(\mathrm{GPa})$ & $(v)$ & $(\mathrm{MPa})$ & $(\gamma)$ & $(\mathrm{C})$ & $\left(Q_{\alpha}\right)$ & $(\mathrm{B})$ \\
200 & 0.3 & 220 & 430 & 35,000 & 142 & 11.7 \\
\hline
\end{tabular}

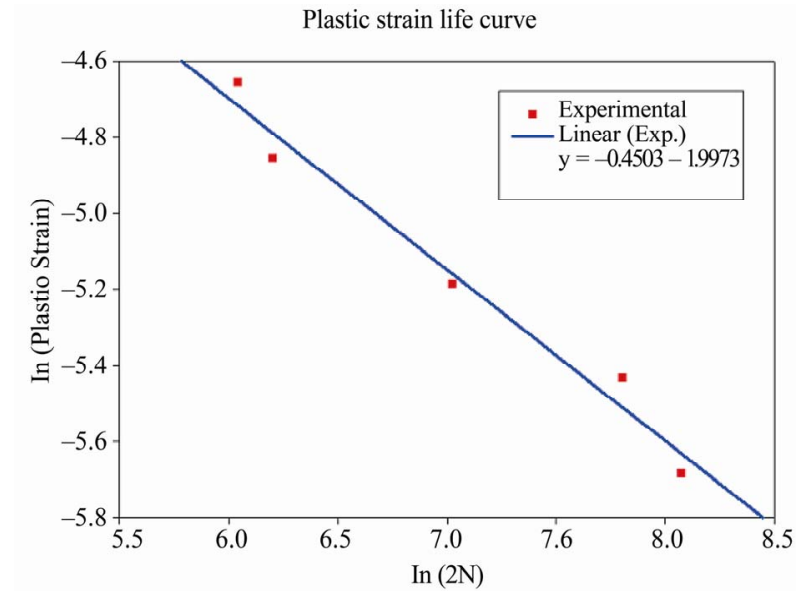

Figure 8. Plast stain-life curve.

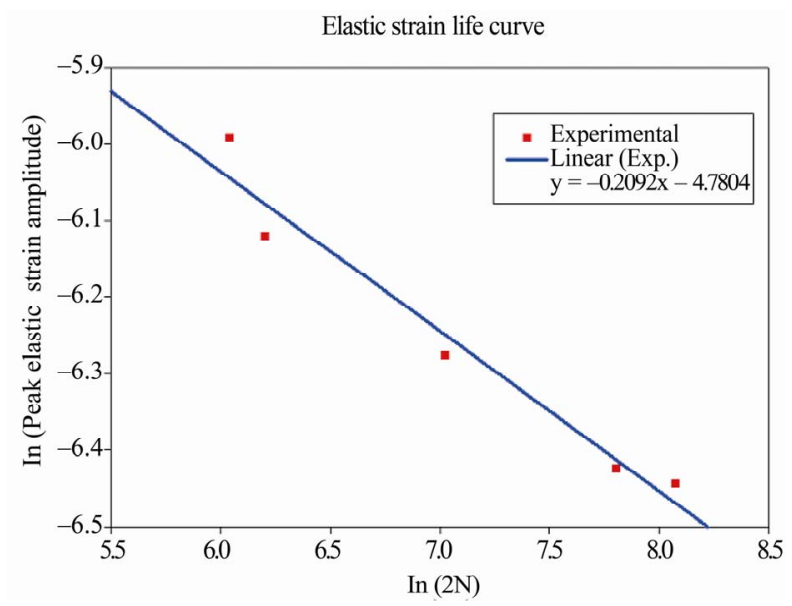

Figure 9. Elastic stain-life curve. 


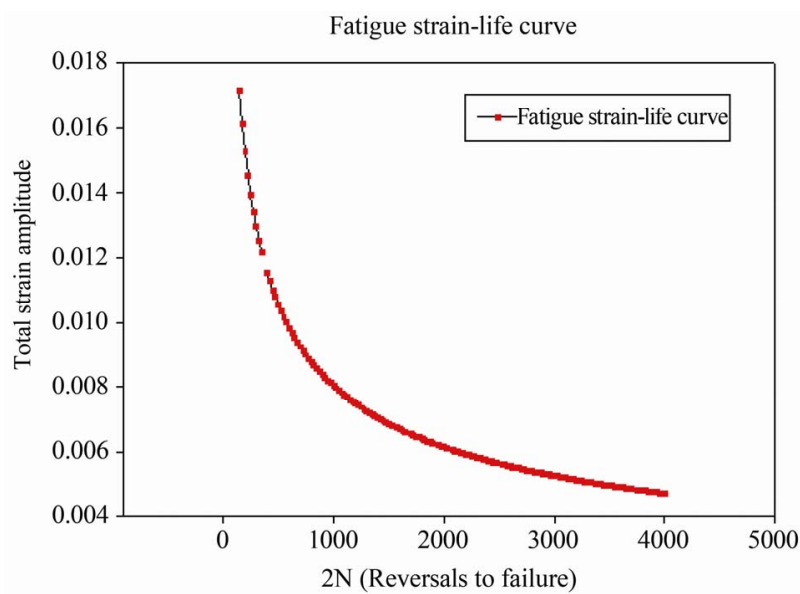

Figure 10. Total stain-life curve.

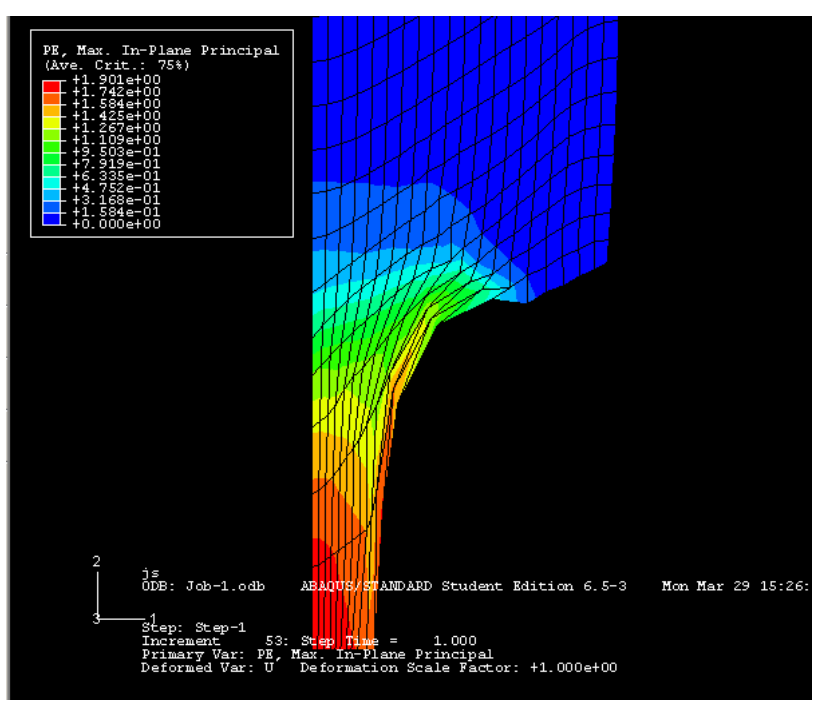

Figure 11. Fe sim ulation of notched specim en in ABAQUS.

\section{Computation of Failure Cycle for Notched Fatigue Specimens}

The failure cycles for different notched specimens are found by following three steps.

1) Material strain-life equation for the whole range has been developed from LCF test data of plain round specimens. This strain life curve is also used for the failure prediction for notched specimen based on actual strain developed at the notch tip at for different strain amplitudes.

2) The maximum strain is evaluated at the notch tip from FE simulation of LCF test of notched specimens.

3) On the basis of this maximum strain obtained from $\mathrm{FE}$ analysis failure cycles for that notched specimen for a given strain amplitude is computed from the material total strain life-equation already developed from LCF test data of plain round specimens.
4) Failure cycles for different notched specimens at different strain amplitudes are found out from experiment and compared with the predicted results.

Notched fatigue specimens are modeled and simulated in FE software ABAQUS using the same material model as used in simulating plain round specimens. The values of different material hardening parameters are also kept same as these are considered to be material constants. The maximum strain for the notch tip element at saturated level is obtained from FE outputs for a particular notched specimen at the given strain amplitude. Putting the value of the strain in the strain life equation developed from LCF test data of plain round specimens the failure cycles $\mathrm{N}$ can be computed. The value of $\mathrm{N}$ thus computed based on maximum strain gives the predicted life of the notched specimen. In this way the predicted lives are computed for 11 different notched specimens of $30^{\circ}, 45^{\circ}, 60^{\circ}$ notch angles and each at different strain amplitudes. Predicted results are compared with the lives determined from experiment. The predicted results along with experimental values for notched specimens of $30^{\circ}$, $45^{\circ}, 60^{\circ}$ notch angles are shown in Figures 12-14 respectively. All the predicted results for all the notched specimens along with experimental values are simultaneously shown in Figure 15. Life cycles for notched specimens are predicted on the basis of maximum strain at crack tip. By joining the points of predicted life at different strain amplitudes the predicted strain life curve can be generated. The actual life for the particular notched fatigue specimens are determined from experiments and compared with the predicted curves.

\section{Results and Discussions}

In this work it is attempted to predict the failure cycles of notched fatigue specimen under strain controlled cyclic loading using strain-life data of plain fatigue specimen

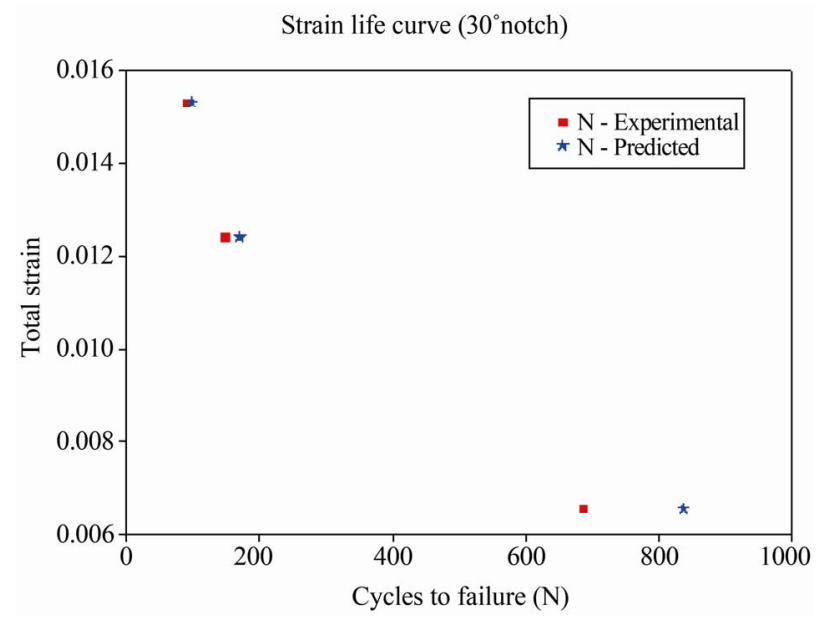

Figure 12. Strain-life curve $30^{\circ}$ notch specimen. 


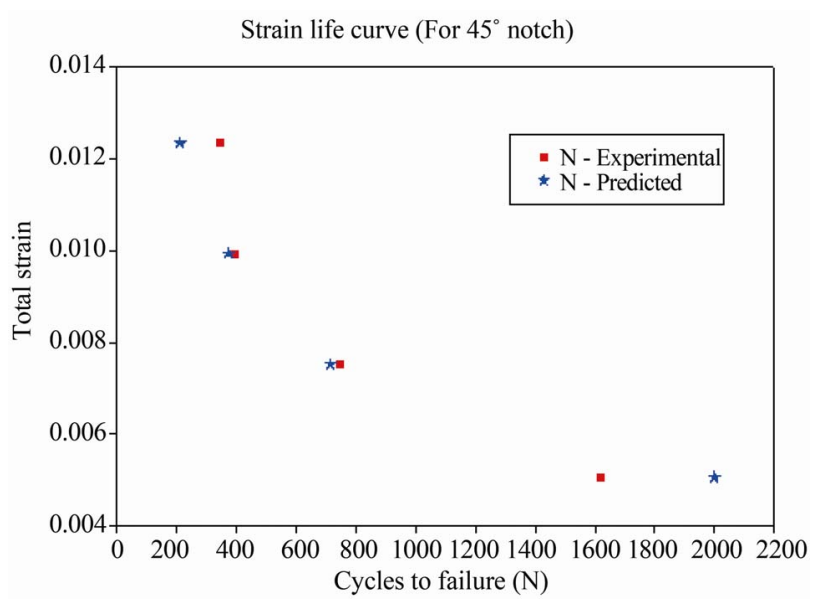

Figure 13. Strain-life curve $45^{\circ}$ notch specimen.

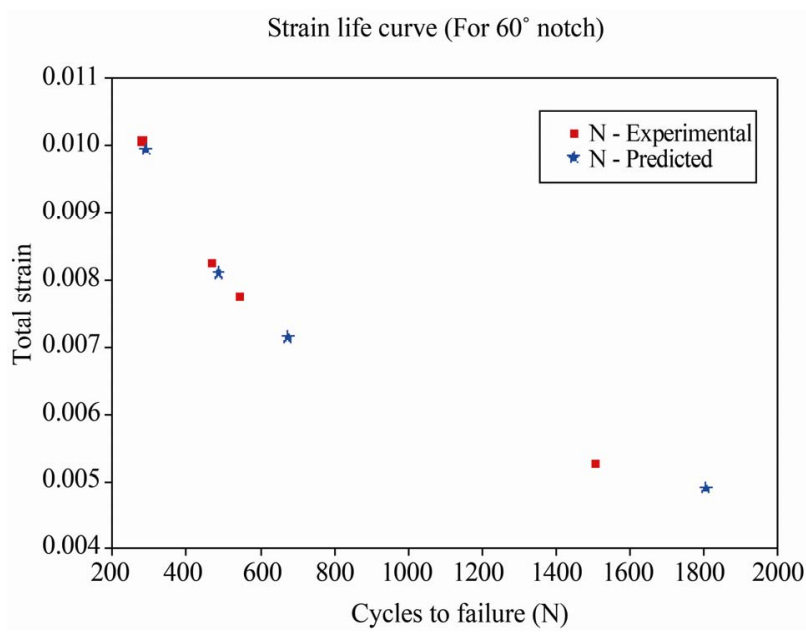

Figure 14. Strain-life curve for $60^{\circ}$ Notch specimen.

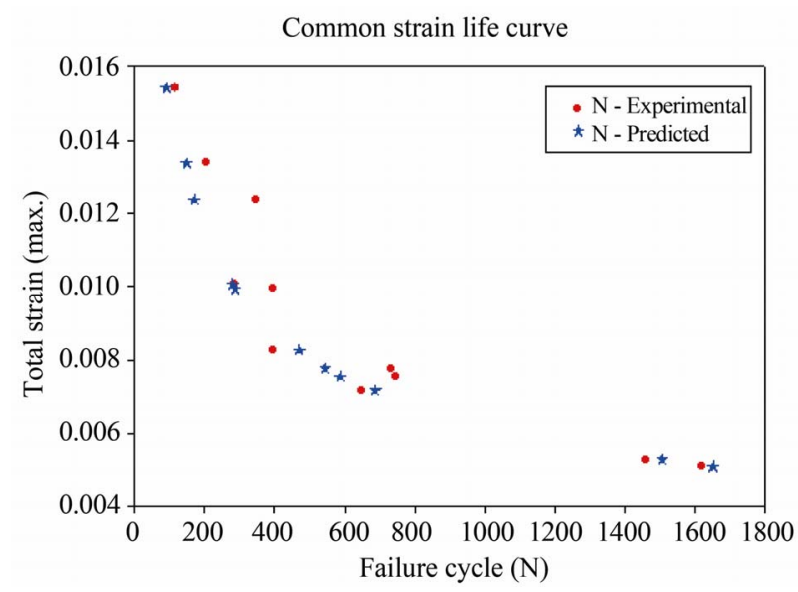

Figure 15. Common strain-life curve.

(without notch) on the basis of maximum strain developed obtained from finite element simulated results of notched specimen under strain controlled cyclic loading.
The accuracy of prediction in this method depends on the correctness of the material total strain-life curve generated from experimental results of LCF data of round specimens and the accuracy of simulated value of maximum strain of notched specimens. The tensile properties of the material have been determined from a large number of samples to minimize errors. Material total strain life curve is generated from LCF tests of wide range of strain amplitudes $(0.3 \%$ to $1.2 \%)$. The failure of the specimen is achieved at the point when the load drop is $60 \%$ of the maximum load. The strain rate and other parameters are maintained same to provide the uniform test environment. The values of the coefficients are found to be of the satisfactory in quality and the order of magnitude.

The accuracy in the prediction of failure cycles from strain life equation highly depends on the accuracy of the evaluation of maximum strain developed due to cyclic loading corresponding to certain strain amplitude. For irregular geometry like notched specimens the evaluation of maximum strain corresponding to certain strain amplitude is accomplished by finite element simulation of notched fatigue specimens under cyclic loading. The accuracy of the predicted strain by FE simulation depends on the selection of appropriate material model and the accuracy of the value of the material parameters used. In Figures 2 and 3 the load vs strain and stress vs strain for the LCF test of round specimen at $0.5 \%$ strain amplitude are shown along with the FE simulated results. The hardening parameters used in FE simulation are extracted from the experimental results of the same test. The predicted results fairly match with the experimental results. Hence the applicability of the Armstrong, Frederick (1966) kinematic hardening model for the simulation of low cycle fatigue test of round specimen is found to be acceptable. Then using the same material model and material parameters the FE simulated results of LCF tests at different strain amplitudes are generated and compared with the experimental results and the values of hardening parameters are tuned. In the Figures 4-7 the peak stresses vs no of cycles from FE simulated and experimental results are plotted and compared. It is appeared from the figures that the predictability of peak stresses for LCF test by this FE simulation is acceptable for different strain amplitudes and also at different no of cycles. Based on these observations this FE simulation method is used to predict the actual maximum strain developed at the notch tip for LCF test of notched specimen.

From the total strain-life curve the failure cycles for any notched specimen is calculated using the maximum total strain obtained from $\mathrm{FE}$ results for $30^{\circ}$ notch angle at different strain amplitudes and from these predictions the total strain (max)-life curve for that notched speci- 
men is obtained. Now the actual failure cycles for that notched specimen is found out from fatigue testing of that notched specimen at that strain amplitude and is compared with predicted results (Figure 11). In this way the similar curves are generated also for specimens with $45^{\circ}$ and $60^{\circ}$ notch angles (Figures 12 and 13). The \% of error in predicted life is also calculated in each case and tabulated in the Table 6. In most of the cases predicted no of cycles are found to be less compared to experimental values. The errors in prediction are found to have no bias regarding strain range or notch angle. Predicted Strain life curves are found to be almost similar for all the three types of notches. The maximum \% of error is found to be 27.7 but the error is within $13 \%$ for most of the cases. From the results it is apparent that the predicttion of failure cycles for notched specimens derived from the strain life data of plain fatigue specimens based on maximum strain developed in the specimen can be used with a little approximation. The common strain life curve generated from specimens of several notch angles gives a better prediction, which is apparent from the Figure 14.

\section{Conclusions}

The final conclusion can be made from the results obtained that the total strain-life curve generated from fatigue test of round specimen can also be used for the pre- diction of life for notched specimens based on actual strain developed at notch tip. The actual strain obtained from FE results based on the Armstrong, Frederick (1966) kinematic hardening model and cyclic hardening material model. Based on this material model the errors in life prediction of notched specimens are found to be random in nature of mean value of -3.90 and standard deviation of 13.22. Hence it can be concluded that if the correct values of actual maximum strain is compared with the fatigue life, the same relationship will be obtained for the same material for any geometry. The Advancement in FE analysis for accurate prediction of strain at the notched cross section can be used for life prediction of life of components having complex geometry or discontinuity. The strain life curve for a material can also be generated using experimental results of notched specimens with correction in strain value to be computed from FE analysis. The method is straightforward and more generalized compared to other methods. The degree of applicability of this method is further to be tested for other type of specimens and notch conditions. From the results it is also observed that in most of the cases the predicted life is found to be less compared to experimental values for all the types of notched specimens. This may be due to the fact that the life has been predicted based on maximum strain in notched section. The actual failure may be

Table 6. Computed and experimental results for failure cycles.

\begin{tabular}{|c|c|c|c|c|c|c|}
\hline Sl No. & Specimen & Total strain (Exp) & Total strain (max) & N (predicted) & N (exp.) & Error (\%) \\
\hline \multicolumn{7}{|c|}{ (Computed) } \\
\hline 1 & NF230 & 0.002 & 0.006534 & 837 & 948 & -11.7 \\
\hline 2 & NF330 & 0.0035 & 0.012538 & 180 & 205 & -12.1 \\
\hline 3 & NF130 & 0.005 & 0.01519 & 102 & 117 & -12.8 \\
\hline 4 & NF345 & 0.0015 & 0.005073 & 1652 & 1619 & 2.03 \\
\hline 5 & NF145 & 0.002 & 0.006965 & 715 & 746 & -4.15 \\
\hline 6 & NF445 & 0.0025 & 0.008935 & 375 & 394 & -5.06 \\
\hline 7 & $\mathrm{NF} 245$ & 0.003 & 0.010123 & 262 & 346 & -24.2 \\
\hline 8 & NF260 & 0.0015 & 0.005257 & 1507 & 1660 & 3.2 \\
\hline 9 & NF160 & 0.002 & 0.007144 & 675 & 731 & -7.6 \\
\hline 10 & NF360 & 0.0025 & 0.008109 & 487 & 397 & 27.7 \\
\hline 11 & NF460 & 0.003 & 0.099862 & 290 & 285 & 1.7 \\
\hline
\end{tabular}


strain in notched section. The actual failure may be governed by the overall stress state in the cross section. Then if the life is predicted on the basis of average strain in the notched cross section a better match may be obtained.

\section{REFERENCES}

[1] Numerous Examples of Fatigue Failures Are Given in Failure Analysis and Prevention, "Metals Handbook," Vol. 10, 8th Edition, American Society for Metals, Metals Park, 1975.

[2] M. A. Miner, Journal of Applied Mechanics, Vol. 12, pp. A159-A164, c1945.

[3] "Manual on Low-Cycle Fatigue Testing," Constant Amplitude Low-Cycle Fatigue Testing, ASTM Standard E606-80, ASTM Specical Technical Publication 465, Philadelphia, 1969.

[4] J. D. Morrow, "Internal Friction, Damping and Cyclic Plasticity," ASTM Specical Technical Publication No. 378, Philadelphia, 1965, p.72.

[5] L. F. Jr. Coffin, "A Study of the Effects of Cyclic Thermal Stresses on a Ductile Metal," Transactions of the ASME, Vol. 76, 1954, pp. 931-950.

[6] S. S. Manson and G. R. Halford, "Practical Implementation of the Double Linear Damage Rule and Damage Curve Approach for Treating Cumulative Fatigue Damage," International Journal of Fracture, Vol. 17, No. 2, 1981, pp. 169-192. doi:10.1007/BF00053519

[7] H. Neuber, "Theory of Stress Concentration for Shear-Strained Prismatical Bodies with Arbitrary Nonlinear StressStrain Law," Journal of Applied Mechanics, Vol. 28, 1961, pp. 544-550. doi:10.1115/1.3641780

[8] T. H. Topper, R. M. Wetzel and J. Morrow, Journal of Materials, Vol. 4, 1969, pp. 200-209.

[9] O. H. Basquin, "The Exponential Law of Endurance Tests," American Society for Testing and Materials Proceedings, Vol. 10, 1910, pp. 625-630.

[10] A. H. Noroozi, G. Glinka and S. Lambert, "A Two Parameter Driving Force for Fatigue Crack Growth Analysis," International Journal of Fatigue, Vol. 27, No. 10-12, 2005, pp. 1277-1296.

doi:10.1016/j.ijfatigue.2005.07.002

[11] O. P. Ostash, V. V. Panasyuk and E. M. Kostyk, "A Unified Model of Initiation and Growth of Fatigue Macrocracks. Part 1. Use of Force Parameters of Fracture Mechanics of Materials at the Stage of Initiation of a Crack," Fiziko-Khimicheskaya Mekhanika Materialov, Vol. 34, No. 1, 1998, pp. 7-21.

[12] K. N. Pandey and S. Chand, "Fatigue Crack Growth Model for Constant Amplitude Loading," Fatigue and Fracture of Engineering Materials and Structures, Vol. 27, No. 1, 2004, pp. 459-472. doi:10.1111/j.1460-2695.2004.00760.x

[13] S. K. Visvanatha, P. V. Straznicky and R. L. Hewit, "Influence of Strain Estimation Methods on Life Predictions Using the Local Strain Approach," International Journal of Fatigue, Vol. 22, No. 8, 2000, pp. 675-681. doi:10.1016/S0142-1123(00)00042-6.

[14] M. Knop, R. Jones, L. Molent and C. Wang, "On the Glinka and Neuber Methods for Calculating Notch Tip Strains under Cyclic Load Spectra," International Journal of Fatigue, Vol. 22, No. 9, 2000, pp. 743-755. doi:10.1016/S0142-1123(00)00061-X

[15] J.-Y. Lim, S.-G. Hong and S.-B. Lee, "Application of Local Stress-Strain Approaches in the Prediction of Fatigue Crack Initiation Life for Cyclically Non-Stabilized and Non-Masing Steel," International Journal of Fatigue, Vol. 27, No. 10-12, 2005, pp. 1653-1660. doi:10.1016/j.ijfatigue.2005.07.014

[16] F. Ding, M. L. Feng and Y. Y. Jiang, "Modeling of Fatigue Crack Growth from a Notch," International Journal of Plasticity, Vol. 23, No. 7, 2007, pp. 1167-1188. doi:10.1016/j.ijplas.2006.10.010

[17] R. Tovo and P. Livieri, "An Implicit Gradient Application to Fatigue of Sharp Notches and Weldments," Engineering Fracture Mechanics, Vol. 74, No. 4, 2007, pp. 515-526. doi:10.1016/j.engfracmech.2006.06.009

[18] D. Kujawski and S. Stoychev, "Internal Stress Effects on Fatigue Crack Initiation at Notches," International Journal of Fatigue, Vol. 29, 2007, pp. 1744-1750. doi:10.1016/j.ijfatigue.2006.12.004

[19] B. Atzori, P. Lazzarin and G. Meneghetti, "Fatigue Strength Assessment of Welded Joints: From the Integration of Paris' Law to a Synthesis Based on the Notch Stress Intensity Factors of the Uncracked Geometries," Engineering Fracture Mechanics, Vol. 75, No. 3-4, 2008, pp. $364-378$. doi:10.1016/j.engfracmech.2007.03.029

[20] M. Benedetti, V. Fontanari, G. Lutjering and J. Albrecht, "The Effect of Notch Plasticity on the Behaviour of Fatigue Cracks Emanating from Edge-Notches in High Strength $\beta$-Titanium Alloys," Engineering Fracture Mechanics, Vol. 75, No. 2, 2008, pp. 169-187. doi:10.1016/j.engfracmech.2007.03.037

[21] M. T. Whittaker, S. J. Williams and W. J. Evans, "Prediction of Fatigue Initiation Lives in Notched Ti 6246 Specimens," International Journal of Fatigue, Vol. 30, No. 4, 2008, pp. 623-634.

doi:10.1016/j.ijfatigue.2007.05.013

[22] W. J. Evans, R. Lancaster, A. Steele, M. Whittaker and N. Jones, "Plain and Notched Fatigue in Nickel Single Crystal Alloys," International Journal of Fatigue, Vol. 31, No. 10, 2009, pp. 1709-1718. doi:10.1016/j.ijfatigue.2009.03.010

[23] S. Giancane, R. Nobile, F. W. Panella and V. Dattoma, "Fatigue Life Prediction of Notched Components Based on a New Nonlinear Continuum Damage Mechanics Model," Procedia Engineering, Vol. 2, No. 1, 2010, pp. 1317-1325. doi:10.1016/j.proeng.2010.03.143

[24] G.-Q. Sun and D.-G. Shang, "Prediction of Fatigue Lifetime under Multiaxial Cyclic Loading Using Finiteelement Analysis," Materials \& Design, Vol. 31, No. 1, 2010, pp. 126-133. doi:10.1016/j.matdes.2009.06.046 
[25] Y. Yamashita, Y. Ueda, H. Kuroki and M. Shinozaki, "Fatigue Life Prediction of Small Notched Ti-6Al-4V Specimens Using Critical Distance," Engineering Fracture Mechanics, Vol. 77, 2010, pp. 1439-1453. doi:10.1016/i.engfracmech.2010.04.001

[26] D. Leidermark, J. Moverareab, K. Simonssona, S. Sjöström and S. Johansson, "Fatigue Crack Initiation in a Notched
Single-Crystal Superalloy Component," Procedia Engineering, Vol. 2, No. 1, 2010, pp. 1067-1075. doi:10.1016/i.proeng.2010.03.115

[27] Z. L. Gao, B. X. Qiu, X. G. Wang and Y. Jiang, "An Investigation of Fatigue of a Notched Member," International Journal of Fatigue, Vol. 32, No. 12, 2010, pp. 1960-1969. doi:10.1016/j.ijfatigue.2010.07.005

\section{List of Symbols}

$\mathrm{N}=$ cycles to failure

$\dot{\varepsilon}_{\mathrm{f}}=$ fatigue ductility coefficient

$\sigma_{f}^{\prime}=$ fatigue strength coefficient

$\Delta \mathrm{e}=$ nominal strain range

$\varepsilon_{\mathrm{t}}=$ total strain

$c=$ fatigue ductility exponent

$\gamma=$ kinematics Hardening parameter

$\mathrm{C}=$ kinematics Hardening parameter
$\Delta \varepsilon_{\mathrm{p}}=$ plastic strain amplitude

$\varepsilon_{e}=$ elastic component of the cyclic strain amplitude

$b=$ fatigue strength exponent

$\Delta \varepsilon=$ local strain range

$\sigma^{0}=$ yield stress

$\mathrm{K}_{\mathrm{t}}=$ stress Concentration Factor

$\varepsilon_{e q}^{p}=$ equivalent plastic strain

$\mathrm{X}=$ back stress at any point 